\title{
Gluten-Free Diet: Always as Easy, Useful, and Healthy as People Think?
}

\author{
Cinthia V. Flores Quan ${ }^{1}$ Susana E. Redecillas Ferreiro ${ }^{1,2}$ Oscar Segarra Cantón ${ }^{1,2}$ \\ ${ }^{1}$ Gastroenterology, Hepatology, Nutritional Support and Pediatric \\ Liver Transplantation Unit, Department of Pediatrics, Hospital \\ Universitari Vall d'Hebron, Barcelona, Spain \\ Address for correspondence Oscar Segarra Cantón, MD, PhD, Passeig \\ Vall Hebron, 119-129 08035 Barcelona, Spain \\ (e-mail: osegarra@vhebron.net).
}

2 Department of Medicine, Universidad Autónoma de Barcelona (UAB), Barcelona, Spain

J Child Sci 2018;8:e75-e81.

\begin{abstract}
A diet free of wheat and other gluten-containing foods is followed by individuals with celiac disease and by unaffected persons. Although the evidence and pathophysiology of gluteninduced symptoms are well established in celiac disease, they are still limited in non-celiac patients. At present, a gluten-free diet is often seen as a healthy lifestyle change instead of an adequate dietary therapy required for a specific condition. Consequently, the market for gluten-free products is steadily growing and improving; in fact, pseudocereals and genetically modified foods and crops are gaining importance in attempts to cover the dietary and nutritional needs of a population that demands it. There is currently interest not only in modifying crops to improve their agronomic traits and product flavor and appearance, but also to improve the nutritional content of crops and/or to silence certain

Keywords

- gluten

- pseudocereals

- celiac disease

- gluten-free diet genes with greater risk of allergenicity. However, the gluten-free diet trend is not hazard free, and many people can end up struggling with dietary disorders after making this decision. Therefore, we should be familiar with and take into account the potential shortage of certain nutrients in some of the gluten-free alternative products, which are now being fortified to prevent nutrient deficiencies and their consequences.
\end{abstract}

\section{Introduction}

The main cereals currently produced worldwide are rice, corn, and wheat, with the latter being the most widely grown in terms of crop surface.

Wheat (Triticum aestivum $L$.) is an irreplaceable source of food in the world, and consumption has gradually risen over the past 100 years. Worldwide production reached 734.5 million tons in 2015, compared with 5 million tons in 2003. The viscoelasticity of wheat-based doughs is the main trait providing an advantage to this grain over other cereals. This property due to gluten has been taken advantage in industry not only when manufacturing doughs, but also as an additive into several foods. This fact could have led to progressive potential overexposure of the population to gluten as well as to attempts to correlate the substance with an increased

received

June 29, 2018

accepted after revision

July 1,2018
Issue Theme Nutrition in Child Health Conditions; Guest Editor: Pilar Codoñer Franch, MD, PhD. prevalence of people who report and/or experience adverse reactions to foods with gluten, despite the lack of evidence or studies to confirm this assumption. ${ }^{1}$

At present, "going gluten-free" is often viewed as a healthy lifestyle choice instead of an appropriate and necessary dietary treatment for a specific condition, namely celiac disease (CD). Consequently, the market for gluten-free products is steadily growing. The latest European reports estimate a year-on-year growth rate of $10.4 \%$ between 2014 and 2019. ${ }^{2}$

These gluten-related disorders have gradually emerged as an epidemiologically relevant phenomenon with an estimated worldwide prevalence around 5\%. The three main classes covered by this term are $\mathrm{CD}$, wheat allergy (WA), and nonceliac gluten sensitivity (NCGS). ${ }^{3}$ 
Wheat grains actually have several components (saccharides and proteins), making it difficult to distinguish or identify what is responsible for improvement when a person starts a gluten-free diet. In terms of nutrition and digestion, several details on the macronutrients of wheat are of interest. Most of the protein contained in wheat germ is gluten, which accounts for $80 \%$ of wheat germ content and is simply a complex mixture of hundreds of different proteins, primarily gliadin and glutenin. ${ }^{4}$ Recently, other gluten-free proteins, inhibitors of $\alpha$-amylase/trypsin, have also been related to gastrointestinal symptoms. Wheat germ agglutinin is a glycoprotein designed to protect wheat crops. This protein can cross the intestinal cell membrane and have a proinflammatory effect, altering intestinal permeability. ${ }^{5}$

Wheat is a cereal rich in short-chain carbohydrates. Oligosaccharides, particularly fructans, may have beneficial prebiotic effects but also occasionally cause functional gastrointestinal symptoms. In contrast, long-chain (nonstarch) carbohydrates play a more important role in bowel frequency and the prevention of colorectal cancer. Nonabsorbable carbohydrates are fermented by intestinal flora, producing short-chain fatty acids, such as butyrate, the essential substrate of colonocytes. Lipid content is extremely low at 1 to $2 \%$, and polyphenols are only found in whole grains.

\section{Gluten-Related Disorders}

The three main conditions that cause digestive and/or extradigestive symptoms in response to gluten intake and that require gluten elimination from the diet are $C D$, WA, and NCGS.

Although not the aim of this review, we will briefly explain how to distinguish between these conditions, to identify their forms of presentation and, above all, to be aware of their different diagnostic criteria and the ease or difficulty to reach a diagnosis.

\section{Celiac Disease}

$\mathrm{CD}$ is an immune-mediated systemic disorder by environmental factors (intake of gluten and prolamins [gliadins, secalins, hordeins, and, possibly, avenins]) in genetically susceptible individuals (HLA-DQ). The condition is characterized by the presence of clinical manifestations; the presence of specific blood antibodies, mainly endomysial antibodies, tissue transglutaminase antibodies, and deamidated gliadin peptide antibodies; the presence of HLA-DQ2 and/or HLA-DQ8 haplotypes; and injury of varying levels to the intestinal mucosa. ${ }^{6}$

The clinical characteristics of $\mathrm{CD}$ differ considerably according to the age of onset. Intestinal symptoms and delayed growth are common in children diagnosed in the first few years of life, whereas extraintestinal symptoms can often appear in late childhood. The clinical picture may vary considerably, from gastrointestinal symptoms such as abdominal pain, vomiting, diarrhea, and/or constipation to general symptoms such as headache, joint pain, and/or apathy.
The disorder is a permanent condition and, therefore, a strict gluten-free diet is the cornerstone of treatment and is recommended as a lifelong practice for both symptomatic and asymptomatic patients, as it will normalize the symptoms as well as laboratory and histology results. ${ }^{7}$

\section{Wheat Allergy}

Wheat allergy is an immunoallergic reaction, namely a type I hypersensitivity reaction to wheat proteins and, therefore, not necessarily to gluten, in which immunoglobulin $\mathrm{E}$ and the release of chemical mediators such as histamine play an essential role. It is characterized by the presence of digestive, respiratory, and/or cutaneous symptoms, triggered by exposure to wheat through mucous membranes (digestion or respiratory) and/or skin. ${ }^{8}$

The clinical characteristics largely depend on exposure to the antigen. The most common digestive symptoms are vomiting and diarrhea after intake. The patient may also experience extradigestive symptoms, for instance, wheatdependent exercise-induced anaphylaxis, atopic dermatitis, urticaria, and asthma or rhinitis. WA may be temporary in children, unlike adults. ${ }^{9}$

\section{Nonceliac Gluten Sensitivity}

Nonceliac gluten sensitivity (NCGS) is the proposed name for the presence of gastrointestinal and extraintestinal symptoms triggered by gluten intake in the absence of specific antibodies for CD and enteropathy, as well as any allergic manifestation. This emerging condition has an estimated prevalence of 10 -fold that of $\mathrm{CD} .{ }^{10}$

The clinical characteristics can be very similar to $C D$. The symptoms described most frequently are abdominal pain (80\%), chronic diarrhea (73\%), fatigue (33\%), bloating (26\%), eczema, headache, blurred vision, depression, anemia, paresthesia in legs, arms, and hands, and joint pain..$^{11,12}$

Unlike CD and WA, which have been studied extensively, NCGS is a relatively new condition, is closely related to other gastrointestinal functional syndromes, and requires a diagnosis of exclusion in the absence of clear diagnostic criteria. ${ }^{13,14}$

\section{Gluten-Free Diet}

In recent decades, the need for gluten-free products has risen due to the increase in the number of patients diagnosed with CD. Celiac patients seek gluten-free products that look and taste the same as products with gluten, without overlooking nutritional aspects. ${ }^{15}$

Gluten is present in cereals such as wheat (Triticum aestivum), rye (Secale cereale), barley (Hordeum vulgare) spelt wheat (Triticum spelta), khorasan wheat (Triticum turgidum), triticale (Triticum sps $\times$ Secale cereale), and several varieties of oats (Avena sativa).

Generally speaking, gluten-free products are of lower quality than their respective gluten-containing counterparts because the structure falls apart easily and the texture is rather dry. Gluten-free cereals and pseudocereals that can be used as alternatives are listed in -Table 1. 
Table 1 Classification of cereals according the presence or absence of gluten

\begin{tabular}{|l|}
\hline $\begin{array}{l}\text { Cereals and cereal products WITH potential presence of } \\
\text { gluten }\end{array}$ \\
\hline Wheat, oats, barley, and rye \\
\hline Spelt wheat \\
\hline Khorasan wheat \\
\hline Couscous and durum wheat \\
\hline Bulgur \\
\hline Udon \\
\hline Seitan \\
\hline Manioc flour \\
\hline $\begin{array}{l}\text { Cereals and cereal products WITHOUT potential presence } \\
\text { of gluten }\end{array}$ \\
\hline Corn, rice, and tapioca \\
\hline Buckwheat \\
\hline Quinoa, amaranth, and teff \\
\hline Sorghum and millet \\
\hline Chia seed and flaxseed \\
\hline Polenta \\
\hline Nut flour \\
\hline
\end{tabular}

In particular, European Commission Regulation No. 41/20091 defines "foodstuffs suitable for people intolerant to gluten" as products intended for a particular diet that have been specially formulated, processed, or prepared to meet the specific nutritional needs of people intolerant to gluten. In this sense, food products made with one or more ingredients from wheat, oats, barley, rye, or their crossbred varieties, which have been specially processed to eliminate gluten shall not contain a gluten level above $100 \mathrm{mg} / \mathrm{kg}$ to be considered gluten-free products.

\section{Types of Cereals in Gluten-Free Products}

\section{Pseudocereals}

Cereals are a major part of the diet of the world population and play an indisputable role in the foundation of the nutritional pyramid recommended by various nutritional guidelines. However, despite the benefits of cereal consumption, they can cause food allergies and intolerances such as CD and NCGS.

Pseudocereals are broad-leaf plants used in the same way as cereals, and their seeds may be milled to flour. Examples of pseudocereals are quinoa, amaranth, and teff, among others. Because of the name, pseudocereals are sometimes thought to be artificial imitations or second-generation foods, but this is a false notion. In terms of botany, cereals belong to the grass family and, therefore, have fine, sharp leaves that become ear heads and yield the grains known as cereals. Conversely, pseudocereals are not part of the grass family and have very broad leaves. They do yield grains and seeds similar to those of grasses and have been used since antiquity in the same way as grass crops, milled as flour and in a wide variety of products, such as bread.

The cultivation of these pseudocereals is gaining importance in the world because they meet the dietary and nutritional needs of the population, and the regions and approaches taken in cultivation are very similar to those of cereals. Even more importantly, pseudocereal derivatives are appropriate for $\mathrm{CD}$ patients because they contain no gluten. ${ }^{16}$ However, the high nutritional value of the pseudocereals carries to their popularity among athletes and vegetarians and goes to an increasing consum. ${ }^{17}$

\section{Nutritional Value of Pseudocereals}

Pseudocereals have a high nutritional value and are rich in carbohydrates, proteins, fiber, and minerals. ${ }^{17}$ Their main carbohydrate is starch, a glucose polymer. A portion of this starch is hydrolyzed and slowly absorbed in the small intestine, whereas a large proportion arrives intact to the large intestine where it is fermented, stimulating natural flora and acting as a prebiotic.

Amaranth starch has different characteristics than wheat. Because it contains less amylose, its capacity to swell when mixed with water is lower, making it less appropriate for breadmaking. In the food industry, this substance is gaining interest due to the properties of its starch as an ideal natural thickener.

Pseudocereals have a higher protein content than wheat or other cereals, and their protein is considered to be easier to digest and with a high biological quality. Protein quality depends on essential amino acid composition, with egg or breast milk protein considered the reference standard due to their high biological value. Pseudocereals have a higher percentage of albumin and globulins than wheat, and their albumins and globulins have a higher content of essential amino acids, particularly lysine, the most limiting amino acid in cereals. Pseudocereals also have a higher content in histidine, cysteine, methionine, and arginine, which contributes to higher protein quality than in the case of wheat.

Quinoa and amaranth have a higher oil content compared with wheat and teff. This oil mainly contains unsaturated fatty acids, most of it linoleic acid. Quinoa oil is rich in tocopherol, whereas amaranth oil contains squalene, an intermediary triterpene in steroid and hormone synthesis.

Quinoa and amaranth have a higher folic acid content than wheat. Both are also important sources of B, C, and E vitamins.

Pseudocereals have higher mineral and trace element content than cereals and are zinc-rich compared with wheat. There are also higher amounts of iron and calcium in amaranth and teff than in wheat, barley, or rice. Like quinoa, teff is also rich in magnesium and potassium.

- Table 2 lists some of the differences in macronutrients between cereals and pseudocereals. ${ }^{18}$

\section{Minor Cereals}

Minor cereals are defined as "minor" because cultivation and consumption are less widespread or well known. In fact, they 
Table 2 Comparative nutritional values of cereals and pseudocereals

\begin{tabular}{|l|l|l|l|l|l|}
\hline & Wheat & Corn & Rice & Quinoa & Amaranth \\
\hline Carbohydrates (\%) & 69.7 & 70 & 74.9 & 60 & 62 \\
\hline Proteins (\%) & 11.6 & 9.8 & 7.7 & 14 & 16 \\
\hline Lysine (\%) & 0.36 & 0.22 & - & 0.89 & 0.89 \\
\hline Methionine (\%) & 0.17 & 0.27 & 0.27 & 0.32 & 0.32 \\
\hline Tryptophan (\%) & 0.14 & 0.07 & 0.1 & 0.15 & 0.15 \\
\hline Fats (\%) & 3.5 & 7 & 2.8 & 5 & 7.5 \\
\hline Fiber (\%) & 2.7 & 1.7 & 1.4 & 4.1 & 12 \\
\hline Energy (kcal $/ 100 \mathrm{~g})$ & 309 & 338 & 353 & 341 & 333 \\
\hline
\end{tabular}

are limited to certain areas of the world. The following are examples of minor cereals, sorghum, and millet, among others.

Sorghum and millet have been basic foods in the semiarid tropical areas of Asia and Africa over the centuries, and currently represent major sources of energy, proteins, vitamins, and minerals for a vast portion of the population in disadvantaged areas. ${ }^{19}$ At present, sorghum and millet are part of new, nontraditional foods and beverages (instant porridges, malt beverages, beers, etc.), and are increasingly used as whole grains to manufacture healthy precooked products, making these minor cereals even more valuable. Historically, sorghum has had a worse reputation than wheat due to its roughness, even though it has nutritional advantages and antidiarrheal (astringent) properties. For centuries, millet has been used as a cereal for breakfast (Great Britain), as flour, or in ready-to-eat meals.

\section{Nutritional Value of Minor Cereals}

Like cereals and pseudocereals, minor cereals' most common carbohydrate is starch, a carbohydrate that is slowly absorbed and has a low glycemic index.

The second most important component of sorghum and millet grains is protein, with the protein content of these grains comparable to wheat and lower than in pseudocereals. Genetic and environmental factors affect the amount of protein and the amino acid profile. A common characteristic between these minor cereals and the others is that lysine is again the limiting amino acid in their composition.

The fat content is higher in these minor cereals than wheat but below the content of pseudocereals (quinoa and amaranth), largely due to unsaturated fats. The fatty acid content in the various minor cereals is similar, with linoleic acid most common, followed by oleic and palmitic oil.

High fiber content (although lower than wheat) and low digestibility are also other characteristic traits of sorghum and millet, which greatly influence consumer acceptability.

In general, whole grains from minor cereals are an important source of B vitamins, most of them found in the outer layers of grain bran. In terms of mineral content, both have a higher zinc content than wheat, with millet also an iron-rich cereal.

\section{Genetically Modified Foods}

After 20 years of positioning on the world market, genetically modified crops such as soybean, corn, cotton, and canola are the most important at the commercial level. However, according to the International Service for the Acquisition of Agri-Biotech, there are more than 25 genetically modified crops approved for marketing, among which the most widely sold in 2014 achieved a total of 181.5 million hectares sown, an increase of 3 to $4 \%$ compared with 2013. These figures are 100 -fold than those of 1996 , when marketing began. ${ }^{20}$

At present, there is not only interest in modifying crops to improve their agronomic traits or their product flavor and appearance but also to improve the nutritional content of crops and/or silence certain genes that can cause allergy. As a result, research is currently underway to silence the gene that codes for wheat gliadins, the proteins associated with gluten content. If the expression of these proteins would be vastly reduced or silenced, people with CD could consume larger amounts of wheat-based products, at a lower cost than at present. Genetically modified lines of wheat with low gliadin content have shown low $\mathrm{T}$ cell reactivity, good breadmaking properties, and excellent palatability.

\section{Preparation of Gluten-Free Products}

Gluten-free food production poses several technological challenges due to the lack of the functionality normally provided by gluten. This lack has required adapting manufacturing formulations and processes to obtain breads, cookies, cakes, pizzas, pastries, and other cereal products with sensory characteristics as similar as possible to gluten equivalents. ${ }^{15}$ Some of the ingredients usually present in the manufacturing of gluten-free bread are starch, dairy products, eggs, soybean protein, and hydrocolloids. The presence of a certain amount of starch significantly improves the quality of gluten-free breads. This requirement is preferably met by using rice, potato, and/or tapioca starches.

Gluten-free products are usually deficient in protein compared with similar products manufactured with wheat flour. Enriching rice flour crackers with 25\% soy meal enhances both protein value, at a low cost, and also improves the sensory characteristics. 
Adding dietary fiber can improve texture and gelling, thickening, and emulsifying capacity, as well as stabilize the properties of gluten-free foods. The fibers most commonly used are derived from corn, oats, and barley. ${ }^{21}$

Hydrocolloids are essential additives used to produce gluten-free breads because they mimic the functionality of gluten to some extent due to their viscosity or viscoelasticity.

The use of natural yeast doughs is an excellent alternative to improve bread quality, as they are natural fermentation initiators. These doughs are obtained by mixing flour, water, and other ingredients and fermenting them with lactic acid bacteria and naturally present yeasts.

Another alternative to improve the quality of gluten-free breads is to use enzymes such as amylases, proteases, hemicellulases, lipases, transglutaminases, and oxidases.

\section{Nutritional Aspects of Gluten-Free Products}

Gluten-free products are usually not enriched or fortified, and are often obtained from refined flours or starches. Consequently, the products do not have the same amount of nutrients as their gluten equivalents. A study by Matos and Rosell ${ }^{15}$ assessed the nutritional value of 11 different kinds of gluten-free breads available in retail supermarkets in Spain. The nutritional composition of commercial gluten-free breads varied between 40 and $62 \%$ carbohydrates, 0 and $8 \%$ proteins, 1 and $11 \%$ fats, and highly variable amounts of fiber (0-6\%). This profile differs considerably from glutencontaining bread products, which have a very similar nutritional composition despite the varieties available. These data reveal the potential nutritional differences caused by continual intake of gluten-free breads if there is no change in nutrient intake from other foods. ${ }^{22}$

Cereal-based gluten-free foods are carbohydrate and fatrich, but deficient in some micronutrients. There have been reports of deficiencies of fiber, thiamin, folate, niacin, riboflavin, calcium, magnesium, iron, and zinc, which have led the industry to include them for the purpose of enhancing the nutritional composition.

These discrepancies in the nutritional profile of glutenfree products and gluten-containing equivalents have led to a reformulation of gluten-free products intended to obtain nutritionally balanced products that provide the necessary nutrients for people who must follow these therapeutic regimens. In addition, gluten-free breads enriched with calcium and inulin have been designed to help correct calcium deficiencies and provide greater dietary fiber intake. $^{23}$

\section{Ingredients and Labeling of Gluten-Free Products}

Product labeling is compulsory and is based directly on two basic consumer rights: the right to safety and the right to information. One of the most important functions of the labeling is to identify who is responsible for the product (e.g., manufacturer, packer, retailer, seller, and/or importer).

The composition limits and labeling of gluten-free foods laid down by European Commission Regulation No. 41/20091 and appropriate for people with gluten intolerance are as follows ${ }^{24}$ :
1. Food products for people with gluten intolerance composed of one or more ingredients from wheat, oats, barley, rye, or their crossbred varieties and specially processed to eliminate gluten shall not contain a gluten level above $100 \mathrm{mg} / \mathrm{kg}$ (ppm) in foods as sold to the final consumer.

2. The labeling, advertising, and packaging of the products listed in point 1 shall mention "very low gluten." The term "gluten-free" may be used if the gluten content is not over $20 \mathrm{mg} / \mathrm{kg}$ (ppm).

3. Oats in foods for people with gluten intolerance must be produced, prepared, or processed to avoid contamination with wheat, barley, rye, or their crossbred varieties, and the gluten content must not be above $20 \mathrm{mg} / \mathrm{kg}$ (ppm).

4. The terms "very low gluten" or "gluten-free" mentioned in sections 2 and 4 should be listed very near the product trade name.

The seal created by the Federation de Celiac Associations of Spain (Federación de Asociaciones de Celíacos de España, FACE) is a seal of approval intended to ensure celiac consumers that products bearing the seal have met the following three requirements ${ }^{25}$ :

- Allow a maximum gluten level of $10 \mathrm{mg} / \mathrm{kg}$ (ppm) in the final product, tested by accredited laboratories as per ISO 17025 for gluten analysis.

- Identify gluten as a hazard in Hazard Analysis and Critical Control Points (HACCP) systems, for the purpose of preventing cross-contamination with gluten.

- Monitor companies' HACCP systems through certification bodies accredited by ENAC as per UNE: EN 45011:98 on the scope of the "Tested by FACE" seal of approval.

This FACE seal can be used by manufacturers of special products for celiac patients (bread, pastries, pasta, etc.) and manufacturers that voluntarily make a special commitment to celiac patients despite manufacturing "nonspecialty or nonrisk" products for celiac individuals (sausages, dairy products, etc.).

FACE pioneered the creation of this Seal of Approval, which is completely innovative at the international level in view of the lack of laws regulating the use of the term "gluten-free." The Seal of Approval is extremely helpful to companies that wish to manufacture gluten-free products, as it offers them clear guidelines and a distinctive mark of quality and safety for consumers with CD.

The European Licensing System and crossed-grain symbol refer to the international gluten-free symbol. It is regulated by the Association of European Celiac Societies, which has delegated granting of its use and control to its member associations. At present, industries that wish to use this symbol must be certified according to the European Licensing System. This symbol is only valid if the Registry No. granted by the association is affixed to the product, along with one of the following expressions:

- Symbol and XX-YYY-ZZZ; the product contains no oats and has less than $20 \mathrm{mg} / \mathrm{kg}$ (ppm) of gluten.

- Symbol and OATS XX-YYY-ZZZ; the product contains pure oats and has less than $20 \mathrm{mg} / \mathrm{kg}$ (ppm) of gluten. 
- Symbol and $100 \mathrm{XX}-\mathrm{YYY}-\mathrm{ZZZ}$; the product contains no oats and has less than $100 \mathrm{mg} / \mathrm{kg}$ (ppm) of gluten.

- Symbol and 100/OATS XX-YYY-ZZZ; the product contains pure oats and has less than $100 \mathrm{mg} / \mathrm{kg}$ (ppm) of gluten.

The phrase "may contain traces of..." refers to the fact that some products list the text "may contain gluten," which means that, although this ingredient has not been included in the food voluntarily, its manufacturer cannot ensure that the product does not contain small amounts or traces thereof, for example, because the product was prepared with the same equipment used to manufacture a product that does contain it.

\section{Nutritional Consequences of a Gluten-Free Diet}

There is ongoing debate on whether it is appropriate to eliminate gluten from the diet if there is no illness to warrant such a measure, as the trend toward "eating gluten-free" is not free of hazards. Some patients who struggle with dietary disorders began their decline with exclusion diets. Going gluten-free deprives a person's diet of many key elements, such as fibers and vitamins, and requires compensation to maintain balanced nutrition. Consequently, over time gluten-free diets can lead to dietary imbalances with deficiencies in some nutrients. The Størsrud group found that celiac patients who include oats in their gluten-free diet had an increased intake of fiber, thiamin, iron, and zinc. ${ }^{26}$

A gluten-free diet can be a healthy diet, but it is often low in fiber, high in fats, and deficient in B-complex vitamins, vitamin $\mathrm{D}$, calcium, and magnesium. In some countries around the world, particularly in Latin America, glutenfree products are not fortified because flour fortification is not used, raising the possibility of nutritional deficiencies. ${ }^{27}$

Gluten-free products often contain higher amounts of carbohydrates and lipids than their gluten-containing equivalents. Segura and Rosell ${ }^{28}$ reported that the nutritional composition of a range of gluten-free breads had a high glycemic index, low protein content, and high fat content. Mariani et $\mathrm{al}^{29}$ studied celiac adolescents and found that their fat and protein intake was higher than recommended. Recent studies show that a gluten-free diet may involve a higher risk of obesity and other cardiovascular risk factors. ${ }^{30}$

Chronic constipation is a common and significant symptom in patients with $\mathrm{CD}$. Some studies have reported that the gluten-free diet is associated with a lower intake of dietary fiber. Almost $15 \%$ of the adult daily fiber intake in the United States comes from yeast bread containing gluten. Unfortunately, most gluten-free grain-based commercial products contain less fiber than their gluten-containing counterparts.

Several studies have observed fat-soluble and watersoluble vitamin deficiencies at the time CD was diagnosed. It would be logical to believe that starting a gluten-free diet and improving intestinal villi atrophy would lead to resolution of vitamin malabsorption; however, nutritional studies on this issue have shown that some vitamin deficiencies tend to persist years after beginning a gluten-free diet. ${ }^{31}$ Folate and thiamin deficiencies after 2 years of gluten-free diet were attributed to the fact that very few gluten-free cereals were fortified with these two vitamins, compared with the common practice of fortification in wheat-based cereals.

Some studies have reported low iron intakes with a gluten-free diet. Thompson observed that 64 of 83 glutenfree cereal products had lower iron quantities than their gluten-containing counterparts. Only 9 of 58 gluten-free breads, pastries, and cold cereals were fortified with iron. There are also reports of lower intakes of calcium, magnesium, zinc, and selenium in patients adhering to gluten-free diet. $^{32}$

\section{Conclusions}

The elevated prevalence of several gluten-mediated gastrointestinal and extraintestinal disorders among the population has meant that gluten-free diet is viewed as a means to achieving a healthier lifestyle. Consequently, the market for gluten-free products is steadily growing.

However, gluten-free diet involves a series of restrictions when rotating carbohydrate-rich products, the base of the food pyramid, as most of those used in our setting are wheat-based. The inclusion of pseudocereals and minor cereals in a gluten-free diet would help keep the diet richer, as well as add balance and variety. Pseudocereals and minor cereals of high nutritional value are more readily available in our setting and are less expensive than other suitable products for celiac patients, making them an extremely reasonable option for all persons who require a glutenfree diet.

Conversely, gluten-free foods derived from cereals are rich in carbohydrates and fats, and deficient in some macronutrients and micronutrients. As a result, a long-term glutenfree diet can lead to deficiencies in some nutrients if the diet is not correctly fortified. The inclusion of omega-3 oil, thiamin, fiber, iron, probiotics, and/or prebiotics is a promising alternative that will improve the nutritional composition of these gluten-free foods.

In short, because gluten-free diet can be harmful for people not requiring it due to the risk of deficiencies in essential nutrients, we recommend that gluten-free diet be used only if necessary, ensuring that the diet also includes pseudocereals, minor cereals, and properly fortified cerealbased gluten-free foods.

\section{Conflict of Interest}

None.

\section{References}

1 Reig-Otero Y, Mañes J, Manyes L. Sensibilidad al gluten no celiaca (SGNC) manejo nutricional de la enfermedad. Nutr Clín Diet Hosp 2017;37:171-182

2 Aziz I, Hadjivassiliou M, Sanders DS. Self-reported gluten sensitivity: an international concept in need of consensus? . Am J Gastroenterol 2014;109(09):1498-1499

3 Buscarini E, Conte D, Cannizzaro R, et al; Italian Association of Hospital Gastroenterologists and Endoscopists (AIGO), Italian Society of Endoscopy (SIED), Italian Society of Gastroenterology (SIGE). White paper of Italian Gastroenterology: delivery of 
services for digestive diseases in Italy: weaknesses and strengths. Dig Liver Dis 2014;46(07):579-589

4 Molina-Rosell C. Alimentos sin gluten derivados de cereales. In: Rodrigo L, Peña AS, eds. Enfermedad celíaca y sensibilidad al gluten no celíaca. Barcelona, Spain: OmniaScience; 2013:447-461

5 Junker Y, Zeissig S, Kim SJ, et al. Wheat amylase trypsin inhibitors drive intestinal inflammation via activation of toll-like receptor 4. J Exp Med 2012;209(13):2395-2408

6 Aranda EA, Araya M. Treating coeliac disease. How do we measure adherence to the gluten-free diet? [Article in Spanish]. Rev Chil Pediatr 2016;87(06):442-448

7 Husby S, Koletzko S, Korponay-Szabó IR, et al; ESPGHAN Working Group on Coeliac Disease Diagnosis; ESPGHAN Gastroenterology Committee; European Society for Pediatric Gastroenterology, Hepatology, and Nutrition. European Society for Pediatric Gastroenterology, Hepatology, and Nutrition guidelines for the diagnosis of coeliac disease. J Pediatr Gastroenterol Nutr 2012;54(01):136-160

8 Sapone A, Bai JC, Ciacci C, et al. Spectrum of gluten-related disorders: consensus on new nomenclature and classification. BMC Med 2012;10:13

9 Pelz BJ, Bryce PJ. Pathophysiology of food allergy. Pediatr Clin North Am 2015;62(06):1363-1375

10 Catassi C, Bai JC, Bonaz B, et al. Non-celiac gluten sensitivity: the new frontier of gluten related disorders. Nutrients 2013;5(10): 3839-3853

11 Tonutti E, Bizzaro N. Diagnosis and classification of celiac disease and gluten sensitivity. Autoimmun Rev 2014;13(4-5):472-476

12 Francavilla R, Cristofori F, Castellaneta S, et al. Clinical, serologic, and histologic features of gluten sensitivity in children. J Pediatr 2014;164(03):463-7.e1

13 Sapone A, Lammers KM, Casolaro V, et al. Divergence of gut permeability and mucosal immune gene expression in two gluten-associated conditions: celiac disease and gluten sensitivity. BMC Med 2011;9:23

14 Krigel A, Lebwohl B. Nonceliac gluten sensitivity. Adv Nutr 2016; 7(06):1105-1110

15 Matos ME, Rosell CM. Relationship between instrumental parameters and sensory characteristics in gluten-free breads. Eur Food Res Technol 2012;235(01):107-117

16 Theethira TG, Dennis M. Celiac disease and the gluten-free diet: consequences and recommendations for improvement. Dig Dis 2015;33(02):175-182

17 Alvarez-Jubete L, Arendt EK, Gallagher E. Nutritive value and chemical composition of pseudocereals as gluten-free ingredients. Int J Food Sci Nutr 2009;60(Suppl 4):240-257
18 Mota C, Santos M, Mauro R, et al. Protein content and amino acids profile of pseudocereals. Food Chem 2016;193:55-61

19 Nout MJ. Rich nutrition from the poorest - cereal fermentations in Africa and Asia. Food Microbiol 2009;26(07):685-692

20 Méndez L, Garro G. Trigo transgénico para celíacos y arroz enriquecido con lisina. Rev Alimentaria 2016;145:25-26

21 Sabanis D, Lebesi D, Tzia C. Development of fibre-enriched gluten-free bread: a response surface methodology study. Int J Food Sci Nutr 2009;60(Suppl 4):174-190

22 Lee AR, Ng DL, Dave E, Ciaccio EJ, Green PH. The effect of substituting alternative grains in the diet on the nutritional profile of the gluten-free diet. J Hum Nutr Diet 2009;22(04): 359-363

23 Krupa U, Rosell CM, Sadowska J, Soral-Smietana M. Bean starch as ingredient for gluten-free bread. J Food Process Preserv 2010; 34(Suppl 2):501-518

24 Commission Regulation (EC) No. 41/2009 Concerning the composition and labelling of food stuffs suitable for people intolerant to gluten. O J L16, 21.01.2009 (V52): 3-5

25 Panillo N, Ariño A. Guía práctica etiquetado sin gluten. Available at: https://www.aragon.es/estaticos/GobiernoAragon/Departamentos/CiudadaniaDerechosSociales/Areas/11_Consumo/05_publicaciones_y_centro_de_documentacion/publicaciones_boletines_informativos/02_folletos/celiacos/etiquetado_sin_gluten.pdf. Accessed February 2018

26 Størsrud S, Hulthén LR, Lenner RA. Beneficial effects of oats in the gluten-free diet of adults with special reference to nutrient status, symptoms and subjective experiences. Br J Nutr 2003;90(01): 101-107

27 Thompson T. Thiamin, riboflavin, and niacin contents of the gluten-free diet: is there cause for concern? J Am Diet Assoc 1999; 99(07):858-862

28 Segura ME, Rosell CM. Chemical composition and starch digestibility of different gluten-free breads. Plant Foods Hum Nutr 2011; 66(03):224-230

29 Mariani P, Viti MG, Montuori M, et al. The gluten-free diet: a nutritional risk factor for adolescents with celiac disease? J Pediatr Gastroenterol Nutr 1998;27(05):519-523

30 Anania C, Pacifico L, Olivero F, Perla FM, Chiesa C. Cardiometabolic risk factors in children with celiac disease on a gluten-free diet. World J Clin Pediatr 2017;6(03):143-148

31 Hallert C, Grant C, Grehn S, et al. Evidence of poor vitamin status in coeliac patients on a gluten-free diet for 10 years. Aliment PharmacolTher 2002;16(07):1333-1339

32 Vici G, Belli L, Biondi M, Polzonetti V. Gluten free diet and nutrient deficiencies: a review. Clin Nutr 2016;35(06):1236-1241 